\title{
Spansk verbal-kongruent betydning: verbet, konstruktionen og det grammatiske aspekt. Et kontrastivt-sprogtypologisk perspektiv.
}

\author{
Johan Pedersen
}

\begin{abstract}
Spanish and typologically related languages are characterized by absence of unaccusativization (Levin \& Rappaport Hovav 1995). According to Horrocks \& Stavrou (2007), the verb-inflected grammatical aspect explains the absence of unaccusativization. Against this view, the article argues that the phenomenon relates to the typologically privileged role of the Spanish verb lexeme. From a usage-based point of view, absence of unaccusativization is understood as an undeveloped possibility of schematization. Spanish constructions are verb-framed and constructional (schematic) patterns only have a secondary role elaborating on the verb-framed core meaning (Pedersen 2019). Grammatical aspect, it is argued, likewise plays a secondary role making the verbal contribution congruent with the intended aspectual meaning.
\end{abstract}

\section{Nøgleord}

spansk, konstruktioner, sprogbrugsbaseret, sprogtypologi, aspekt

\section{Baggrund}

Sammenlignet med engelsk afspejler læsningen af den spanske sætning i meget høj grad verbets leksikalske betydning: 


$\begin{array}{llll}\text { Pedro bajó } & \text { a } & \text { la playa } & \text { Spansk } \\ \text { Pedro moved down } & \text { to } & \text { the beach }\end{array}$

$\begin{array}{llll}\text { *Pedro bailó } & \text { a la playa } & \text { Spansk } \\ \text { Pedro danced } & \text { to the beach }\end{array}$

I den typiske spanske sætning i (1), er den intenderede læsning direkte afspejlet i verbets leksikalske betydning (' $\mathrm{X}$ bevæger sig i en bestemt retning mod et mål'). Det er den til gengæld ikke i (2), som er ugrammatisk. Den ugrammatiske mål-orienterede brug af verber med betydningen 'bevægelsesmåde', som i (2), refererer man ofte til i litteraturen som absence of unaccusativization (fx Levin \& Rappaport Hovav 1995). Sprog der som spansk kan karakteriseres ved absence of unaccusativization, refererer jeg til i artiklen som B-sprog, over for A-sprog, som dansk og engelsk, der tillader unaccusativization.

I artiklen viser jeg at en sprogbrugsbaseret tilgang til et sprogs grammatik ændrer det sprogtypologiske perspektiv. I stedet for at tale om absence of unaccusativization i et B-sprog som spansk, med refererence til en universel leksikalistisk tilgang (fx Levin \& Rappaport Hovav 1995), kan vi med en sprogbrugsbaseret tilgang forstå fænomenet som en mulighed for skematisering af sætningen (clausal schematization) i A-sprog, og en tilsvarende anderledes og mere begrænset mulighed i B-sprog. Med skematisering mener jeg når vi bruger indlærte generaliseringer over sprogbrugen i form af abstrakte form-betydningspar som fx [SUBJ V OBL] / ' $\mathrm{X}$ moves $\mathrm{Y}$ ' som skabeloner i konstruktionen af sætningens betydning.

Det spanske verbum i tempus datid er obligatorisk bøjet i grammatisk aspekt, som i (1) hvor det har perfektivt aspekt. Spørgsmålet er nu: hvilken rolle spiller grammatisk aspekt i forhold til fænomenet absence of unaccusativization / clausal schematization? Vi ved at der er en sammenhæng mellem verbets leksikalske betydning og sætningens argumentstruktur og aspektstruktur. Vi ved også at mange andre B-sprog ligesom spansk har grammatisk aspekt. Det omtales ofte som viewpoint aspect.

Jeg vil først præsentere og diskutere en universel leksikalistisk tilgang til absence of unaccusativization hvor verbets grammatiske aspekt spiller en hovedrolle i forklaringen af dette fænomen (Horrocks \& Stavrou 2007). Jeg vil herefter præsentere den alternative sprogbrugsbaserede tilgang, hvor det grammatiske aspekt spiller en helt anden og mere sekundær rolle. 


\section{Grammatisk aspekt og absence of unaccusativi- zation}

Verbet er i spansk og typologisk beslægtede sprog der ligesom spansk er karakteriseret ved såkaldt absence of unaccusativization, bøjet i grammatisk aspekt: perfektivt vs. imperfektivt aspekt. Det er derfor en rimelig hypotese at der på et eller andet plan er en sammenhæng mellem dette fænomen og eksistensen af grammatisk aspekt.

Horrocks \& Stavrou (2007) argumenterer netop for en sådan sammenhæng. De ræsonnerer at den mål-orienterede brug af verber med den leksikalske betydning 'bevægelsesmåde' muliggøres af en universel lexical rule of unaccusativization (fx Levin \& Rappaport Hovav 1995). Denne regel er, ifølge Horrocks \& Stavrou (2007), systematisk blokeret i græsk og typologisk beslægtede sprog, fx spansk, på grund af den obligatoriske aspektmarkering i verbet:

\section{Pedro *bailaba/*bailó a la playa}

'Pedro dansede ned til stranden'

Horrock og Stavrou's idé er at det grammatiske aspektvalg i disse sprog bestemmer en grammatisk lukket atelisk aktivitetsbetydning (bailaba/bailó 'hun dansede'/'hun dansede i en afgrænset periode'), som er inkompatibel med en telisk brug af verbet (jf. den leksikalske regel om unaccusativization) i en målorienteret konstruktion ('... ned til stranden'). En resultativ brug af de fleste verber af denne type i græsk og andre sprog med lignende aspektsystemer er udelukket, ifølge Horrock og Stavrou, simpelthen fordi en inakkusativ læsning af verbet altid vil implicere en ugrammatisk ændring af verbets grammatisk fikserede aspekt fra ikke-terminativt (med udstrækning, 土afgrænset) til terminativt (der nås et mål, \pm iterativt).

Noget lignende ville til sammenligning være, argumenterer Horrocks og Stavrou, hvis vi i den samme sætning forsøger at ignorere en grammatisk betydning, der er morfologisk kodet i verbet:

De forklarer at betydningen af datid i (4), der er indbygget og grammatisk fikseret i verbets form (shot), ikke kan annulleres af et adverbial der refererer ud i fremtiden. I dansk og engelsk, hvor simple verbalformer ikke markeres grammatisk for aspekt, skal verbets aspekt ikke tilskrives en grammatisk værdi. Når verbet vælges er dets status som inergativt eller inakkusativt foreløbig 
og kan endeligt bestemmes i den syntaktiske kontekst. Med andre ord, der bliver ikke blokeret for at verbet kan realiseres i en målorienteret konstruktion via den leksikalske regel om unaccusativization; se fx oversættelsen i (3).

Hvis vi fokuserer på spansk, er der to hovedproblemer i Horrocks og Stavrou's analyse. For det første koder spansk kun for grammatisk aspekt i verbets datidsformer. Horrocks \& Stavrou (2007) baserer analysen på data fra klassisk græsk og nygræsk, og generaliserer derudfra til typologisk beslægtede sprog som spansk. I græsk er aspektsystemet navnlig på ét punkt forskelligt fra det spanske. Ethvert valg af verbum implicerer et valg af view point aspekt, ud over verbets aktionsart. I spansk er verbets grammatiske aspekt og tempus integreret i datidsbøjningen. Spansk har altså kun grammatisk aspekt i datid, ikke i nutid. Det betyder at muligheden $( \pm)$ for en sprogbrug hvor verbet bruges i historisk nutid i udtryk af typen så løber/ vralter han ind på verelset, vil kunne indikere om absence of unaccusativization skyldes eksistensen af grammatisk aspekt som foreslået af Horrocks og Stavrou, eller om det primært skyldes noget andet. For det andet, ligesom Horrocks og Stavrou's analyse for så vidt angår spansk er begrænset til brugen af verberne i datidssammenhæng, giver den os heller ikke indsigt $\mathrm{i}$ hvorfor brugen af bevægelsesverberne er underlagt lignende begrænsninger i forskellige varianter af den retningsbestemte bevægelseskonstruktion. For eksempel, præcis den samme gruppe af spanske verber der ikke kan bruges i den typiske intransitive mål-orienterede konstruktion, som i (2), kan heller ikke forekomme i transitive bevægelseskonstruktioner (transitive (self) directed motion, TDM), jf. (6):

$$
\begin{aligned}
& \text { Bajó el río } \\
& \text { 'he went down the river' } \\
& \text { *Remó el río } \\
& \text { 'he paddled the river' }
\end{aligned}
$$

Fra et teori-internt synspunkt kan principperne i Horrocks og Stavrou's aspektanalyse ikke umiddelbart overføres til denne variant, idet der vanskeligt kan argumenteres for at sætningens aspektstruktur i (6) systematisk blokeres grammatisk af verbets aspektbøjning. Den transitive bevægelseskonstruktion i (6) implicerer ikke nødvendigvis, som i (3), en terminativ situation (accomplishment/achievement). Der sker derfor ikke nødvendigvis en ændring af verbets grammatisk fikserede aspekt fra ikke-terminativ (aktivitet med udstrækning) til terminativ. TDM-konstruktionen er en form for rumlig udfoldelse/udmåling af den verbale proces ved hjælp af objektet (Tenny 
1994, Pedersen 2019), hvilket er fuldstændig kompatibelt med verbets ateliske aktivitet. Det er ikke desto mindre påfaldende at der alligevel er en delvist sammenfaldende restriktiv brug af bevægelsesverberne $\mathrm{i}$ de to varianter af bevægelseskonstruktionen. Dette indikerer at der må være systematiske begrænsninger i brugen af de spanske bevægelsesverber i de to konstruktioner, som man ikke finder tilsvarende i sprog som engelsk og dansk, og som ikke kan tilskrives en blokering af aspektstrukturen som følge af verbets aspektbøjning. Med andre ord, Horrocks og Stavrou's aspekthypotese egner sig ikke til at lave sammenhængende analyser af konstruktionsvarianterne. Alternativt kan vi fokusere på den rolle verballeksemet har i disse sætningskonstruktioner i spansk, og betragte den rolle verbets grammatiske aspekt har som et afledt fænomen.

\section{En leksikalsk-konstruktionsgrammatisk typologi}

Når vi sætter fokus på det spanske verballeksems rolle i sætningen og det kontrastive perspektiv, kommer vi ikke uden om Leonard Talmy's kognitivesemantiske typologi. Hans typologiske arbejde kortlægger basale formbetydningspar, bl.a. i bevægelseskonstruktioner på tværs af sprog (fx Talmy 1985, 2000). Det er et centralt element i typologien at en række sprog, som i store træk er sammenfaldende med de sprog der kan karakteriseres ved at have absence of unaccusativization, koder 'Bevægelse' + 'Retning' i verbet (verb-framed), og 'Måde' fakultativt i et verbal-uafhængigt adverbielt led, typisk gerundium. Spansk fremhæves ofte som repræsentant for denne gruppe. Heroverfor kategoriserer Talmy andre sprog, fx germanske sprog som dansk og engelsk, som typisk har 'Retning' kodet uden for verbet i en satellit (satellite-framed) - typisk i en partikel og/eller en præpositionsforbindelse - og som har 'Måde' kodet i verbet.

$$
\begin{aligned}
& \text { Pedro salió a la calle (corriendo) } \\
& \text { 'Pedro bevægede sig ud på gaden løbende' }
\end{aligned}
$$

Pedro ran out on the street

Satellite-framed

$$
\text { Pedro løb ud på gaden }
$$

Satellite-framed

Typologien har gennem de seneste 30 år været kritiseret for ikke at kunne tage højde for omfattende afvigelser fra de foreslåede typologiske mønstre. Flere studier har fx vist at sprog som er kategoriseret som verb-framed, alligevel kan 
udtrykke bevægelsesmåden centralt i verbet, fx med verber som correr 'at løbe', der i deres betydning har et element af directed displacement (fx Pedersen 2014):
Pedro corrió al baño
Spansk
'Pedro løb ud på toilettet'

Det er en udfordring for Talmy-orienterede typologiske beskrivelser at der i mange sprog er en del verber der både har betydningselementer af 'Måde' og 'Retning', og som derved kommer i konflikt med typologiens basale form-betydningspar (fx [Verb] / 'Motion, Path' i romanske sprog og [Verb] / 'Motion, Manner' i germanske sprog). Det er også blevet påvist at Talmy's typologi nødvendigvis må udvides til at være tre-delt fordi nogle sprog, fx Thai og Emai (Nigeria), er karakteriseret ved såkaldte serial verb constructions, hvor både 'Path’ og 'Manner' er kodet verbalt i sætningen, enten i forskellige verber, eller i ét verbum med kompleks verbalstamme (se diskussionen og specifikke referencer i Beavers 2010). I visse typologiske beskrivelser har man derfor ud over verb-framed og satellite-framed, indført en tredje typologisk kategori: equipollently-framed languages (Slobin Zlatev \& Yangklang 2004; Slobin 2006).

Talmy's typologi (verb-framed vs. satellite-framed) har dog i mange sammenhænge overlevet kritikken fordi typologien identificerer eksistensen at nogle ubestrideligt vigtige typologiske træk på tværs af et stort antal sprog, og fordi den udpeger centrale typologiske forskelle i de vest-europæiske sprog (romanske vs. germanske sprog). Når vi taler om sprognormer i undervisningssammenhæng, er det også vigtigt at kunne pege på hvad der er god og karakteristisk sprogbrug, og hvad der ikke er.

Det viser sig imidlertid at der er varianter af bevægelseskonstruktionen, $\mathrm{fx}$ TDM-konstruktionen (se ovenfor), men også andre, fx caused-motion konstruktioner, som giver mere fundamentale problemer for den Talmy-orienterede typologi. Eksempel (11) er fx en helt almindelig transitiv bevægelseskonstruktion (TDM) i engelsk med et intransitivt telisk retningsverbum; og (13) og (14) er helt almindelige forekomster af den spanske TDM-konstruktion med henholdsvis telisk og atelisk verbum. Eksempler med Manner verbs af typen $\mathrm{i}$ (12) er desuden acceptabel sprogbrug for engelske sprogbrugere. Omvendt ville brugen af teliske verber af typen i (15) være klart ugrammatisk for spanske sprogbrugere. Disse intra-lingvistiske og tvær-lingvistiske variationer i sprogbrugen kan ikke blot tilskrives marginal variation. Tilsammen er de fundamentalt i konflikt med Talmy's typologiske grundmønstre (se ovenfor). Det er de fordi man i denne konstruktion vanskeligt kan tale om at en 
satellit spiller en central rolle for betydningen i engelsk (satellite-framed??), og det er de fordi verber med betydningen 'Manner' ofte forekommer som hovedverbum i denne konstruktion i spansk, jf. (14), hvilket ikke passer godt sammen med Talmy's typologi. Endelig er en række spanske retningsverber, der er prototypiske spanske bevægelsesverber i Talmy's typologi, systematisk udelukket i denne variant, jf. (15).

$$
\text { Peter entered the house }
$$

Peter paddled the river

Pedro bajó las escaleras

'Pedro descended the stairs'

Pedro saltó la valla

'Pedro jumped the fence'

*Pedro entró la casa

'Pedro entered the house'
Engelsk

Engelsk

Spansk

Spansk

Spansk

Talmy's fokus på form-betydningspar i sætningens syntagmatiske dimension (fx dansk: verbum-måde og satellit-retning) er forankret i en kompositionel syntaktisk-semantisk tradition, og i en klassificerende-beskrivende sprogtypologisk tradition. Jeg foreslår en tilgang til disse typologiske forskelle som i stedet fokuserer på hvorvidt vores L1-tilegnelse foreskriver at sætningens konstruktion skal baseres på verbet og den betydningsstruktur der kan organiseres omkring verbet (= verb framing), eller om sætningskonstruktionen skal baseres på bestemte indlærte konstruktionsmønstre.

Tomasellos arbejde har vist at børns evne til at konstruere sætninger starter med hvad han kalder verb island constructions, som bliver produktive når de centreres omkring brugen af bestemte verber i bestemte ledkombinationer (fx Tomasello 2002). Senere lærer børnene at lave sætninger ud fra de konstruktionsmønstre de har lært, som de kombinerer med verber på nye måder (Diessel 2013). Det er i princippet, og lidt simplificeret, det der gør at engelske og danske sprogbrugere ikke har problemer med sætninger af typen i (2), selvom de måske ikke har hørt dem før, og formentlig finder dem usædvanlige.

Spanske sprogbrugere lærer til gengæld ud fra et konstant sprogligt input at det fortsat er en stærk (sprogbrugsbaseret) verb framing-regel der spiller 
den centrale rolle i sætningskonstruktionen. De lærer at der er en betydningsmæssig overensstemmelse mellem verbets betydning og sætningens kernebetydning. Med indlærte konstruktionsmønstre som skabeloner, implementerer de den verbalbaserede kernebetydning i konkrete konstruktioner, der ofte tilføjer supplerende elementer. Fx kan en gerundium-konstruktion - uafhængigt af det centrale verbum - tilføje 'bevægelsesmåden’ i spansk; se eksempel (7) (Pedersen 2014, 2016, 2019). Implementeringen af den verbalbaserede argumentstruktur i en konkret konstruktion ved brug af indlærte konstruktionsmønstre som skabeloner kalder jeg argument structure construal.

Den verbale rolle i konstruktionen bliver typologisk afgørende (dvs. om det er verbet der bidrager med sætningens kernebetydning), og det bliver ikke nødvendigvis afgørende om verbets leksikalske betydning kan defineres som Path eller Manner (sml. Tesniere 1956; Talmy 1985, 2000) eller som abstrakt vs. specifik (sml. Herslund \& Baron 2005 og Henrik H. Müllers artikel i dette nummer). Med hensyn til at indføre equipollently-framed languages som en tredje typologisk kategori (Slobin Zlatev \& Yangklang 2004; Slobin 2006), så overflødiggøres den som teoretisk kategori i modellen, simpelthen fordi sådanne sprog blot repræsenterer mere komplekse former for verbal-baseret konstruktion. Kategorien er selvfølgelig relevant hvis man ønsker at lave en finmasket klassifikation af sprogene. Typologien har altså på den ene side sprog der er karakteriseret ved at indlærte konstruktionsmønstre (fx intransitiv bevægelse: [SUBJ V OBL]) med en abstrakt betydning ( $\mathrm{fx}$ ' $\mathrm{X}$ moves $\mathrm{Y}^{\prime}$ ) kan udgøre sætningens fundament, og specificeres af verbet; og på den anden side sprog der har verbal-baserede konstruktioner, hvor den verbale kernebetydning manifesterer sig i forskellige indlærte konstruktionsmønstre (dette sidste vil jeg komme tilbage til).

Denne alternative hypotese om de typologiske forskelle giver svar på et $\mathrm{i}$ konstruktionsgrammatisk sammenhæng essentielt spørgsmål, som er relateret til spørgsmålet om absence of unaccusativization i eksempel (2). Hvorfor kan spanske sprogbrugere ikke via generalisering bruge et konstruktionsmønster af typen [SUBJ V OBL] / 'X moves Y', som de har lært fra et hyppigt mønster som (1), til at konstruere en lignende sætning, blot med verbet bailar 'to dance', der har betydningen 'bevægelsesmåde'?
Pedro bajó a la playa
'Pedro bevægede sig ned til stranden'
[SUBJ V OBL] / 'X moves Y'
Verb framing of directed motion 
(2) *Pedro bailó a la playa

'Pedro dansede ned til stranden'

[SUBJ V OBL] / 'X moves Y'

*Verb framing of directed motion

Mit bud på en forklaring er, som skitseret ovenfor, at henholdsvis den verbale verb framing og indlærte konstruktionsmønstre spiller en forskellig rolle $\mathrm{i}$ forskellige sprog, fx i spansk og dansk/engelsk. Eksempel (2) er ugrammatisk fordi spansk ikke giver mulighed for at lægge et indlært konstruktionsmønster til grund for sætningens konstruktion, og fordi verbet (bailar 'at danse') ikke har den nødvendige leksikalske kernebetydning ('at bevæge sig et sted hen') som det forventes ifølge den sprogbrugsbaserede regel i spansk om verbalbaseret konstruktion. Til gengæld er (16) en mulighed, selvom verbets betydning er 'bevægelsesmåde'.
Fernando corrió a su cuarto
'Fernando løb ned på sit værelse'
$\mathrm{X}$ moves in some direction
Kernebetydning via Verb framing
[SUBJ V OBL] / 'X moves Y' Indlært konstruktionsmønster

Correr 'at løbe' har et element af directed displacement, som kan bidrage med en relevant kernebetydning ('X bevæger sig i en retning') i forhold til det vi ønsker at sige (mål-orienteret bevægelse). 'Målet' kodes på konstruktionsniveauet ud fra en passende intransitiv skabelon, jf. den hyppige sprogbrug i (1).

Ligesom det spanske bevægelsesverbums betydning kan være mere eller mindre præcis som sætningens kernebetydning (sml. bajar 'bevæge sig ned' og correr 'løbe i en retning'), kan også et indlært konstruktionsmønster i engelsk/dansk der skal bidrage med sætningens kernebetydning, i særlige kontekster optræde i en uventet anvendelse.

Two people stumbled in the room. The woman.... As she walked in....

Den mål-orienterede fortolkning af den lokative konstruktion er i (17) acceptabel i særlige rumlige kontekster, hvor vi ser situationen fra et punkt lige foran den dør de vælter ind ad (se Nikitita 2008; Beavers 2010). Vi ville her normalt forvente en mål-markør: into (the room) i en mål-orienteret konstruktionen, og in-markøren i en lokativ læsning. 


\section{Grammatisk aspekt som aspect construal}

En spansk sætningskonstruktion implicerer, ifølge den typologiske model, hvad jeg har kaldt argument structure construal af en verbalbaseret argumentstruktur. Det er samtidig en syntaktisk manifestation af aspektstrukturen. Verbets grammatiske aspekt kan man betragte som en uafhængig construal af aspektstrukturen der bringer den verbal-baserede aspektbetydning i overensstemmelse med den syntaktiske manifestation af aspektstrukturen (fx tidsadverbialer) og med aspektstrukturen i den omgivende tekst/kontekst (forgrundsplaner vs. baggrundsplaner). Verbets grammatiske aspekt (aspect construal) opfattes hermed som endnu en indikation på at den spanske sætningskonstruktion er udpræget verbal-baseret, og dybt forankret i den første L1-sprogindlæring (se ovenfor). I en sprogbrugsbaseret model som den jeg foreslår her, er obligatorisk verbalbøjet grammatisk aspekt der indekserer sætningens og kontekstens aspektstruktur, endnu et sprogbrugselement (ud over at sætningsbetydningen afspejler verbets betydning) der konstant bidrager til en stærk verb framing regel i den spanske sprogbrugers grammatik. Grammatisk aspekt er dermed ikke et begrænsende element for visse verbal-kategoriers brug i sætningen (absence of unaccusativization), sådan som det er argumentationen i Horrocks \& Stavrou's (2007) universelt orienterede leksikalistiske tilgang. Grammatisk aspekt er derimod en integreret del af den verbal-baserede sætningskonstruktion i spansk, men med en sekundær rolle sammenlignet med verbets leksikalske betydning.

Fernando bajọ/aba a la playa a las cinco

'Fernando tog ned til stranden kl. 5'

\section{Fernando vivía/ió en Madrid}

'Fernando boede i Madrid'

I eksempel (18) vil den teliske verbalhandling og den mål-orienterede konstruktion forventeligt være afspejlet $\mathrm{i}$ brugen af perfektivt grammatisk aspekt (-ó), mens det imperfektive aspekt (-aba), der markerer det uafgrænsede, udtrykker iterativ læsning, fx at hændelsen gentager sig hver dag. I (19) matcher brugen af det imperfektive grammatiske aspekt (-ia) den ateliske tilstand med udstrækning i verbets og konstruktionens betydning, mens det perfektive aspekt (-ió) der markerer en grænse, markerer at tilstanden gælder i en afgrænset periode. I begge eksempler kan vi i den danske oversættelse eksplicitere læsningen, men vi behøver ikke at gøre det: 'Fernando tog ned til stranden kl. 5 (den dag/hver dag)' / 'Fernando boede i Madrid (på det 
tidspunkt/i den periode)'. I de spanske versioner kan vi ligeledes eksplicitere læsningen, specielt når den er aspektuelt markeret i forhold til verbets aktionsart: Fernando bajaba a la playa a las cinco todos los días 'Fernando tog ned til stranden kl. 5 hver dag'; Fernando vivió en Madrid durante dos años 'Fernando boede i Madrid to år'. Det særlige ved spansk er at uanset om sætningens aspektuelle læsning er ekspliciteret i form af adverbialer eller lignende i sætningen, eller i konteksten på anden vis, er den obligatorisk indekseret som grammatisk aspekt i verbet.

En lille gruppe imperfektive verber har en potentiel inkoativ læsning. Det perfektive grammatiske aspekt (præteritumformen) indekserer her den markerede inkoative læsning. Imperfektumformen indekserer den umarkerede imperfektive tilstandslæsning:

(20a) Pedro sabía que iban a venir

'Pedro vidste at de ville komme'

(20b) Pedro supo que iban a venir

'Pedro fik at vide at de ville komme'
Imperfektum: umarkeret imperfektiv læsning

Præteritum: markeret inkoativ læsning

Perfektivt grammatisk aspekt kan ikke direkte forbindes med den inkoative læsning. Det ses af at verber der ikke har en potentiel inkoativ læsning, aldrig kan få det blot fordi verbet bøjes i perfektivt grammatisk aspekt. Eksempelvis kan et højfrekvent verbum som estar 'at være' ikke give inkoativ læsning via perfektivt aspekt i verbet, jf. (21c) (-uvo):

(21a) Se durmóio en dos minutos

'She fell asleep in two minutes'

(21b) Se quedó dormida en dos minutos

'She fell asleep in two minutes'

(21c) ??estuvo dormida en dos minutos

'She fell asleep in two minutes'

Vi må her i stedet vælge et verbum der i sig selv har inkoativ betydning, jf. (21a), eventuelt et hjælpeverbum med denne betydning, jf. (21b), således at den verbal-baserede betydning kan være i overensstemmelse med tidsadverbialet og den intenderede inkoative læsning. 
Engelsk har ikke altid overensstemmelse mellem verbets betydning og en inkoativ kontekst, hverken i form af verbets leksikalske betydning, eller i form af en grammatisk indeksering i verbet:

(22) She was asleep in ten minutes

(De Swart 2012: 771)

I (22) læses verbets ateliske tilstand pragmatisk med sætningens inkoative betydning. I De Swart beskrives fænomenet som aspectual coercion. I (23) ser vi i dansk en tilsvarende pragmatisk inkoativ læsning:

(23) Hendes mand ville se på bådene, men ved vandet blæste det endnu mere, og hun var irriteret over hans begejstrede snak; og hun var glad [= 'hun blev glad'] da de ikke længere skulle se på både, og sagde at hun også syntes det havde været interessant...

(Roulund 1981: 7)

Her ville vi heller ikke kunne lave en parallel spansk version selvom en spansk version af udtrykket hun var glad, isoleret set, er højfrekvent, se (24a).

(24a) ??Estaba/??estuvo contenta (*'hun var glad = hun blev glad') cuando ya habian terminado de mirar los barcos... ('da de ikke længere skulle se på både...')

Den tilsigtede inkoative betydning skal være tilstede i verbet og indekseres grammatisk. Den kan ikke opnås ved hjælp af en pragmatisk aspektlæsning som i engelsk og dansk. I stedet må vi også her vælge et verbum der leksikalsk har den inkoative betydning, jf. (24b).

(24b) Se puso contenta ('hun blev glad') cuando ya habiamos terminado de mirar los barcos 'da de ikke længere skulle se på både...'

\section{Absence of unaccusativization i nutids-konstruk- tioner}

I spansk er verbet i tempus nutid ikke markeret for grammatisk aspekt. Det betyder at aspektstrukturen i sætningen udelukkende kan tilskrives verbets leksikalske betydning og den syntaktiske realisering i sætningskonstruktionen. En læsning af tempus nutid som 'historisk nutid' kan manifestere sig i en 
konstruktion med en mål-orienteret aspektstruktur der svarer til en parallel konstruktion med verbet i tempus datid. I (25) - (28) viser autentiske eksempler fra korpusdata (Corpus del Español), med verber der udtrykker bevægelsesmåde i den målorienterede konstruktion, helt de samme brugsmønstre, uanset om verbet er brugt i tempus datid, eller i tempus nutid (med historisk læsning). Blandt gruppen af verber med betydningen 'bevægelsesmåde' fandt jeg udelukkende verber af typen correr 'at løbe', dvs. verber med 'directed displacement (DD)'-komponenten, i denne konstruktion, og både $\mathrm{i}$ den sædvanlige tempus datid, jf. (25)-(26), og i tempus nutid, jf. (27)-(28).

(25) Cuando ya se le hacía imposible evitar el llanto, se levantó y corrió a su cuarto

'when she couldn't avoid crying, she got up and ran to her room'

(26) Se levantó del sofá de un salto, como si alguien lo hubiera asustado, 'She jumped up from the sofa, as if someone had scared her, y corrió a la mesa, se sentó y comió and ran to the table, sat down and began to eat'

(27) Corre a la sala ¿dónde está Elena? Busca en su cuarto, ... 'she runs to the living room where is Elena? She looks for her in her room'

(28) Carola corre a su cuarto asustada y cierra la puerta con llave 'Carola runs to her room, terrified, and locks the door'

Verber som bailar 'at danse', der ikke har DD-komponenten i sin leksikalske betydning, fandt jeg ikke i den mål-orienterede konstruktion, hverken i tempus datid, som i (29), eller i tempus nutid, som i (30).

*Pedro bailó a la playa

'Pedro dansede ned til stranden'
* María baila al jardín
'María danser ud i haven'

Disse data knytter ikke fænomenet absence of unaccusativization sammen med eksistensen af grammatisk aspekt. Til gengæld illustrerer de den svaghed i Horrock og Stavrou's aspekt-hypotese (Horrock \& Stavrou 2007), som 
jeg diskuterede i afsnit 2. Hypotesen udfoldes nemlig med udgangspunkt i græsk, hvor verbet altid er markeret for grammatisk aspekt, både i datids- og nutidssammenhæng. Derefter generaliserer Horrock og Stavrou hypotesen til også at gælde for typologisk beslægtede sprog som spansk, uden at de går nærmere ind i de problemer der er forbundet med at grammatiske kategorier er sprogspecifikke (fx Croft 2001; se også diskussionen i Peter Harder \& Kasper Boye's artikel i dette nummer).

Observationerne underbygger på den anden side min hypotese om at den spanske verbalbetydning generelt har en i sprogtypologisk forstand privilegeret rolle i sætningskonstruktionen. Betydningselementer der kan tilskrives konstruktionens abstrakte niveau (indlærte konstruktionsmønstre eller grammatikaliseret aspekt) spiller en integreret men sekundær rolle (hhv. argument structure construal og aspect construal) der er afhængig af den verbalbestemte kernebetydning (til forskel fra fx dansk og engelsk, hvor indlærte konstruktionsmønstre via schematization kan være fundamentet for en mere fleksibel, kreativ og uventet brug af verber). Jeg foreslår at det er dér vi skal finde forklaringen på fænomenet absence of unaccusativization i spansk, vel at mærke hvis vi anlægger et sprogbrugsbaseret sprogsyn.

\section{Konklusion}

Jeg foreslår en sprogbrugsbaseret tilgang til fænomenet absence of unaccusativization, hvor den rolle henholdsvis verbet og indlærte konstruktionsmønstre har i spansk og typologisk beslægtede sprog (B-sprog) er forskellig fra den rolle de har i fx dansk og engelsk (A-sprog). I modellen er sætningskonstruktionen i spansk baseret på en verbal konstruktionsstrategi fra den tidligste L1-indlæring. De indlærte konstruktionsmønstre får en sekundær rolle, som skabeloner for den endelige udformning af konstruktionen. Brugen af de fleste verber med betydningen 'bevægelsesmåde' i en mål-orienteret sætningskonstruktion bliver derfor ugrammatisk fordi verbet ikke er i overensstemmelse med sætningens kernebetydning. I denne model sikrer verbets grammatiske aspekt at det verbale bidrag til betydningen er kongruent med sætningens aspektstruktur i den konkrete kontekst.

I engelsk og sprogtypologisk beslægtede sprog (A-sprog) har de indlærte konstruktionsmønstre en mere central rolle i den forstand at de kan være en skabelon for kodningen af sætningens kernebetydning (skema-baserede konstruktioner). Det åbner mulighed for en fleksibel og kreativ brug af verber, herunder verber med betydningen 'bevægelsesmåde', i sætningskonstruktioner med målorienteret betydning, uden at verbets betydning 
nødvendigvis skal afspejle sætningens intenderede kernebetydning. Det man traditionelt refererer til som unaccusativization, bliver således i den foreslåede model forstået som en mulighed for skematisering af sætningens kernebetydning (schematization).

Jeg har i artiklen rettet opmærksomheden på en række forhold der ikke underbygger Horrocks \& Stavrous (2007) universelle leksikalistiske tilgang, hvor absence of unaccusativization skyldes en grammatisk aspektblokering af den målorienterede konstruktions aspektstruktur. Fx har jeg vist at verbalbrugen i de spanske konstruktioner er underlagt de samme restriktioner uanset om verbet er markeret for grammatisk aspekt. Det er verbet ikke i de historiske nutidskonstruktioner af den samme målorienterede betydning, hvor tempus er nutid. Dette underbygger til gengæld hypotesen om at den spanske verbalbetydning generelt har en i sprogtypologisk forstand privilegeret rolle i sætningskonstruktionen, mens den generaliserede grammatiske betydning tilsvarende har en mere sekundær rolle.

\section{Om forfatteren}

Johan Pedersen, lektor ph.d., Institut for Engelsk, Germansk og Romansk, Københavns Universitet.

\section{Litteratur}

Beavers, J., Levin, B \& Tham, S. W. (2010): The typology of motion expressions revisited. Journal of Linguistics 46(3), 1-58.

Croft, W. (2001): Radical construction grammar. Oxford: Oxford University Press. De Swart, H. (2012): Verbal aspect. I: The Oxford Handbook of Tense and Aspect. Binnick, R. I. (red.). New York: Oxford University Express, 752-780.

Goldberg, A. E. (2006): Constructions at work. The nature of generalization in language. Oxford: Oxford University Press.

Harder, P. \& Boye, K. (2019): Artikel i dette nummer.

Herslund, M \& Baron, I. (2005): Langues endocentriques et langues exocentriques. Approche typologique du danois, du français et de l'anglais. I: Herslund, M. \& Baron, I. (red.). Le génie de la langue française. Perspectives typologiques et contrastives. Langue française 145. Paris: Larousse, 35-53.

Horrocks, G \& Stavrou, M. (2007): Grammaticalized aspect and spatiotemporal culmination. Lingua 117, 605-644.

Levin, B. \& Rappaport Hovav, M. (1995): Unaccusativity: At the Syntax Lexicalsemantics Interface. MIT Press, Cambridge, MA and London. 
Müller, H. H. (2019) Artikel i dette nummer.

Nikitina, T. (2008): Pragmatic factors and variation in the expression of spatial goals: The case of into vs. I: Syntax and semantics of spatial $P$. Asbury, A., Dotlacil, J., Gehrke, B. \& Nouwen, R. (red.). Amsterdam: John Benjamin, 175-209.

Pedersen, J. (2014): Variable type framing in Spanish constructions of directed motion. I: Romance perspectives on construction grammar. Boas, $\mathrm{H}$. C. \& García, F. G. (red.). Book series: Constructional approaches to language, CAL 15. Amsterdam: John Benjamins, 269-304.

Pedersen, J. (2016): Spanish constructions of directed motion - a quantitative study: Typological variation and framing strategy. I: Corpus-based Approaches to Construction Grammar, CAL 19. Yoon, J. \& Gries, S. T. H. Amsterdam: John Benjamins, 105-144.

Pedersen, J. (2019): Verb-based vs. schema-based constructions and their variability: On the Spanish transitive directed motion construction in a contrastive perspective. Linguistics, 57(3), 473-530.

Roulund, G. (1981): Verdito. Noveller. København: Rhodos.

Talmy, L. (1985): Lexicalization patterns: Semantic structure in lexical forms. I: Language typology and syntactic description (vol. 3): Grammatical categories and the lexicon. Shopen, T. (red.). Cambridge: Cambridge University Press, 57-149.

Talmy, L. (2000): Toward a cognitive semantics. Vol.1 and 2. MA Cambridge: MIT Press.

Tenny, C. (1995): How motion verbs are special: The interaction of semantic and pragmatic information in aspectual verb meanings. Pragmatics $\mathcal{E}^{\circ}$ Cognition 3(1), 31-73.

Tesnière, L. (1959) : Eléments de syntaxe structurale. Paris: Klincksieck.

Tomasello, M. (2002): The evolution of grammar in early child language. I: The evolution of language out of Pre-language. Talmy, G. \& Malle, B. F. (red.), 309-328. Amsterdam: John Benjamins. 